\title{
Surveillance \& Society David Murakami Wood's 'Situating Surveillance Studies'
}

\author{
Sean P. Hier \\ Department of Sociology, University of Victoria, Canada. shier@uvic.ca
}

\section{Josh Greenberg}

School of Journalism and Communication, Carleton University, Canada.

\section{Purpose}

This commentary is an invited response to David Murakami Wood's review of The Surveillance Studies Reader (Murakami Wood 2009). We present a general response to the tone and tenor of his unprovoked attack on our book, and we briefly describe a possible research direction for scholars interested in investigating the many aspects of surveillance, politics, power, and inequality.

\section{Comments}

We admit it: we are English-speaking North American social scientists who published an undergraduate reader to introduce students to the study of surveillance and to better inform them about surveillance as a sociological phenomenon. Our primary aim was to bring together a number of provocative readings for students beginning university-level studies of surveillance, and in doing so to take "one more step towards developing a coherent statement on surveillance studies" (Hier and Greenberg 2007: 6). Along with a Senior Editor at the Open University Press who commissioned the volume, we identified a gap in the teaching literature pertaining to the problems posed by unchecked social monitoring and thereby attempted to begin filling it.

We are guilty of many things: we did not commission original contributions, alternatively organizing our volume thematically by drawing on previously published work that captures key elements in the study of surveillance; we did not incorporate or identify every conceivable contribution from all corners of the globe (but see Murakami Wood 2009), alternatively drawing on many Anglo-American contributions, some of which are well-known to surveillance instructors and others that, we felt, should become better known $^{1}$; we faced limitations concerning space and content, forcing us to debate and ultimately negotiate the tension between our ideal publication vision and the demands and expectations of the publisher; and,

\footnotetext{
1 Murakami Wood recognizes that the production of a reader involves making difficult choices (in the confines of space limitations imposed by publishers) that inevitably result in undesirable exclusions from the final product. At the same time, he presents an over-inflated bibliography pointing to all the sources we should have included. We can only imagine how long (and expensive) our reader would be if we incorporated even half of Murakami Wood's suggestions.
} 
perhaps most damning of all, we did not ask the Managing Editor of Surveillance \& Society —a specialty journal devoted to advancing surveillance studies - for permission to carry out these pedagogical tasks.

In light of Murakami Wood's tone and tenor in "Situating Surveillance Studies," our response is organized around three general disclaimers. We do so because greater clarity and explanation are needed to address his many cursory comments and attributions. We do not respond to all of the points presented in his essay but rather provide an overview of the broader context that we believe informs his review article. We do so to provide readers with a background that will enable them to make up their own minds about the value of The Surveillance Studies Reader.

The first disclaimer concerns our professional orientations and aims - a subtle and strange fascination in Murakami Wood's review article. We are both sociologists who specialize in social problems construction, focusing on issues relating to communication, mass media, politics, and power. Neither of us purports to practice an unadulterated form of surveillance scholarship, and we do not place ourselves on par with the world's leading figure in surveillance studies, David Lyon. Nor do we see ourselves as "hip young tyros" (Murakami Wood, p. 57) striving to challenge or displace the canonical status of Professor Lyon (whose work we respect even as we seek to challenge it and push it further).

As sociologists who find themselves writing on surveillance, we aim to develop insights informed by a social problems perspective about a growing set of social injustices in which surveillance practices and technologies are centrally implicated. Part of this research agenda entails producing engaging teaching materials to make students more aware of the problems that surveillance systems can pose for individuals, not all of whom live in North America (e.g., Hier and Greenberg 2007). Another part of this research agenda entails producing scholarly materials to develop frameworks that can explain the relationship between surveillance practices and social problems (see Hier 2003 and 2004; Hier and Lyon 2004; Walby and Hier 2005 and 2009; Hier, Walby, and Greenberg 2006; Hier, Greenberg, Walby, and Lett 2007; Hier and Greenberg 2009; Hier 2010).

The second disclaimer has to do with the appropriateness of this response article and of the article to which it responds. We agree with Murakami Wood that it is important to debate and discuss studies about surveillance and the emergence of a nascent field that is becoming recognized as "Surveillance Studies." At the same time, we have an uneasy feeling that a complete response to Murakami Wood's article would amount to nothing more than a self-indulgent exercise responding to an unambiguously self-indulgent one. We therefore only briefly respond to the tone of Murakami Wood's article in the first portion of our commentary, rather than to the specific contents, and focus the rest of the article on identifying a possible direction for surveillance researchers.

In plain terms, we believe that Murakami Wood exercised poor judgment in his role as Managing Editor when he published a 9-page, non-refereed, dismissive review article focusing on two books with different origins, objectives, and designs. His review article seemingly demonstrated the number of citations one can pack into a review article, leaving us to wonder if his motivation had less to do with our work than it did with his own desire to demonstrate how much he has read on the topic of surveillance. Murakami Wood appears to be motivated by more than just innocent intellectual objectives, an issue to which we now turn.

The third disclaimer is potentially most damaging to the area of surveillance studies as an emerging intellectual enterprise, and it is the most relevant for our orientation in the surveillance literature (see below). When we were initially approached by the Open University Press to develop The Surveillance Studies Reader, we submitted a Prospectus that went through blind vetting by six international reviewers. The final organizational structure and the reading selections were based in part on the guidance and recommendations gleaned through the blind vetting process, as well as on negotiations and collaboration with our editor at the press. 
In the last stage of production, the publisher sought permission to reprint selected reading passages from previously published chapters and journal articles. Two of these papers initially appeared as research articles in Surveillance \& Society after having completed that journal's peer-review process. The first paper originally appeared in the launch issue of the journal, presumably presented to establish the importance of surveillance as a field of academic inquiry. The second paper originally appeared in the third issue of Surveillance \& Society, presented alongside nine other original essays to reflect "what we hope is both our increasing recognition as a serious but innovative project, and our growing transdisciplinary range" (Wood 2003: 234).

To our great surprise, in January 2007 we received notification from our development editor that members of the Editorial Board of Surveillance and Society had challenged the inclusion of certain unidentified materials; had raised concerns about the direction of the volume; and had suggested that the publication of a reader with the wrong passages - and under the wrong, definitive-sounding title - might damage the reputation of the Open University Press.

Our initial amusement at the ethos of academic culture quickly gave way to a disturbing sense of unprofessionalism when we realized the seriousness of the intellectual crime we were alleged to be in the process of committing. In our written response to the Editorial Board, we argued that their attempted interference brought to mind a set of gatekeepers seeking to maintain intellectual control over the production of knowledge, that it was inappropriate in the context of the rigorous review process we had endured, and that it reminded us of Thomas Kuhn's writings on the taken-for-granted, paradigmatic assumptions that inform scientific research activities. We argued that The Surveillance Studies Reader was not designed to appeal to every surveillance scholar and teacher, but rather that it conformed to an internal logic organized by six coherent themes and based on reading selections from major contributors to the field of surveillance studies and others whose work, we believe, merits greater attention. We also informed members of the Editorial Board that the structure of the book had been worked out collaboratively with the publisher, based in part on the critical comments forwarded by six anonymous international referees. The latter declaration put the matter to rest-or so we thought.

Our third disclaimer, therefore, is thus: We suspect that there is something more profound and less evident informing the tone of David Murakami Wood's attack on our book. To borrow from his own scholarly reasoning (see Murakami Wood 2009 p. 58, last line), we cannot give a definitive answer for why he would present an essay of the kind he did. Considering the tenor of Murakami's review article, however, let us suggest several possibilities, including: first, the disappointment that he felt, as Managing Editor of Surveillance \& Society, in failing to control the production of our teaching reader (a reader replete with "critical thinking questions" and suggested further readings); second, the priority he places on the production of original scholarship by "surveillance studies" researchers over teaching materials produced to appeal foremost to students; third, his frustrations that he did not produce a reader on surveillance before us; and fourth, a genuine interest in setting things right in the unsettled world of surveillance studies.

In short, if David Murakami Wood wishes to initiate dialogue on situating surveillance studies, and if he believes that mugging a teaching reader on surveillance studies is the best place to start, then we believe that the readers of this journal should be aware of the broader context that possibly informs his attack.

\section{Now What?}

We were invited to not only respond to Murakami Wood's review article, but to also comment on the direction of surveillance studies.

When Pierre Bourdieu famously remarked, La Sociologie est un sport de combat, he meant that sociology is a means of self-defense and that scholars (not simply sociologists) should act responsibly, operate with professional integrity, and avoid using the discipline to launch unfair attacks. When Bourdieu 
characterized the discipline in this way, he had in mind, we think, the tensions and conflicts inherent in the sociological imperative to inform public discourse, engage in socially relevant activities, and to do things that matter. And yet, here we find ourselves in the all-too-common inconsequential trenches of subdisciplinary insecurity - an identity crisis brought to the level of an event. The value of the forum before us is not, as Professor Murakami Wood conceives of it, to squabble over the virginal purity of surveillance studies but rather to find innovative and useful ways to mount a conceptual, theoretical, and empirical defense against the growing tyranny of surveillance.

Here is a very brief overview of our contribution to the imperative that stands before surveillance studies. As we have recently explained elsewhere (Hier and Greenberg 2009), although the walls of the panopticon have been effectively scaled down - if not torn down altogether (Haggerty 2006) - the surveillance literature has not yet fully broken from the logic of visualization that is found in the panoptic model. Haggerty and Ericson's $(2006,2000)$ work on the politics of surveillance represents one of the most promising developments in surveillance theory over the last decade. We make this argument because their work offers a viable explanation for how surveillance systems work, and it attempts to theorize the nuances of diverse surveillance applications. The important insights of their work notwithstanding, we argue that they do not go far enough to theorize the differential applications and socio-political effects of surveillance systems. This is in part due, we argue, to explanatory limitations that derive from predecessor selection, paradigm building, and the dynamics of intellectual communities.

We also argue that key surveillance scholars, especially Lyon (2007) and Haggerty and Ericson (2006, 2000), have identified the significance of visibility as a guiding concept in intellectual investigation. The problem is that their otherwise excellent contributions entail a descriptive notion of visibility that inadvertently feeds into an undifferentiated theory of power. In our new book, we explain how they endorse a normative conception of visibility as entailing those who are "touched" by surveillance systems. Drawing from Brighenti (2007), we alternatively maintain that visibility is as much a political field as it is an aesthetic perception. Over twelve original research chapters, the book explores an analytical category of visibility by examining numerous social and political issues, including childhood obesity, identity theft, DNA databanks, military power and propaganda, and the surveillance of marginalized populations through welfare regimes, over-policing, and liquor control board interdiction lists.

We conclude by arguing that it is necessary to differentiate two empirically related but analytically distinct research foci: one on surveillance and one on political and social problems. The first analytical interest on surveillance must show how surveillance possesses defining features or characteristics. In the absence of a clear set of criteria to define surveillance qua surveillance, conceptual confusion will continue to detract from the analytical value and political significance of surveillance studies. By encouraging an independent analytical focus on surveillance qua surveillance without recourse to its applications, we are better able to address Haggerty and Ericson's (2006) frustrations with the problematic nature of a broad, undifferentiated theory of surveillance. We are also able to resist their contention that we can no longer speak of inherent attributes to identify surveillance qua surveillance.

The second analytical interest lies in political and social problems. It is necessary to critically assess how information gleaned from assemblages of data affect population groups in fields of visibility differentially, inequitably, and temporally. The differential applications of surveillance systems pertain to populations long disadvantaged by data gathering and analysis (e.g., visible minorities, welfare recipients, children and youth, people in contact with the streets, and so on), but also to populations whose members are otherwise in privileged social positions (e.g., identity theft victims).

Hence, our aim is to identify a place to begin to think differently about surveillance and political problems and to refine our knowledge of how surveillance can be understood as a political and social problem with structural foundations, an argument in keeping with foundational analyses of surveillance (e.g., Rule, Giddens, Dandeker Gandy, Marx, Lyon). We do not wish to foster or exacerbate prolonged academic debate about how to conceptualize surveillance; academic debate is important to gain full understanding 
of surveillance and political problems, but it can also work against the practical imperatives of surveillance research and social change. We therefore encourage surveillance and political problems researchers to probe deeper into the politics of surveillance and visibility, and we offer a viable if incomplete set of theoretical and conceptual insights to accomplish the task at hand.

\section{Acknowledgements}

We thank Kevin Haggerty for the opportunity to publish this response to the review of our book. It goes without saying that we implore readers of Surveillance and Society to not only consult The Surveillance Studies Reader, but also our new book, Surveillance: Power, Problems and Politics, for a more elaborate and convincing version of the argument outlined above.

\section{References}

Brighenti, Andrea. 2007. Visibility: A Category for the Social Sciences. Current Sociology 55(3): 323-342.

Greenberg, Josh and Sean P. Hier. 2009. CCTV Surveillance and the Poverty of Media Discourse. Canadian Journal of Communication, 34(3): 461-86.

Haggerty, Kevin D. 2006. Tear Down the Walls: On Demolishing the Panopticon. In D. Lyon's, ed., Theorizing Surveillance: The Panopticon and Beyond, 23-45. Cullompton: Willan.

Haggerty, Kevin D. and Richard V. Ericson. 2006. The New Politics of Surveillance and Visibility. In Haggerty, Kevin D. and Richard V. Ericson, eds. The New Politics of Surveillance and Visibility, 3-34. Toronto: University of Toronto Press.

Haggerty, Kevin D. and Richard V. Ericson. 2000. The Surveillant Assemblage.” British Journal of Sociology 51(4): 605-62

Hier, Sean P. 2004. "Risky Spaces and Dangerous Spaces: Urban Surveillance, Social Disorder and CCTV. Social and Legal Studies, 13(4): 541-554

Hier, Sean P. 2003. Probing the Surveillant Assemblage: On the Dialects of Surveillance Practices as Processes of Social Control. Surveillance and Society, 1(3): 399-411.

Hier, Sean P. and Josh Greenberg (eds.) 2009. Surveillance: Power, Problems, and Politics. Vancouver: University of British Columbia Press.

Hier, Sean P. and Josh Greenberg (eds.) 2007 (eds.). The Surveillance Studies Reader. UK: Open University Press.

Hier, Sean P. and David Lyon (2004) Surveillance, Technology and the Management of Risk. Guest Editors for International Sociology, 19(2): 131-4.

Hier, Sean P., Kevin Walby and Josh Greenberg 2006. Supplementing the Panoptic Paradigm: Surveillance, Moral Governance, and CCTV. In D. Lyon's Theorizing Surveillance: The Panopticon and Beyond. Cullompton, UK: Willan Publishing, 228-242.

Hier, Sean P., Josh Greenberg, Kevin Walby, and Dan Lett. 2007. Media, Communication, and the Establishment of Public Camera Surveillance Programs in Canada. Media, Culture and Society, 29(5): 727-751.

Lyon, David. 2007. Surveillance Studies: An Overview. Cambridge: Polity.

Murakami Wood, David. 2009. Situating Surveillance Studies. Surveillance and Society, 6(1): 52-61.

Walby, Kevin and Sean. P. Hier. 2009. Securing Citizenship: Identity Cards, Secure Passports, and Border Surveillance in Canada. In S. Rollings-Magnusson's Anti-Terrorism: Security and Insecurity After 9/11. Halifax: Fernwood Press, 125-138.

Walby, Kevin and Sean. P. Hier. 2005. Risk Technologies and the Securitization of Post-9/11Citizenship: The Case of National ID Cards in Canada. Socialist Studies, 1(2): 7-31.

Wood, David. 2003. Foucault and Panopticism Revisited. Surveillance and Society 1(3): 234-239 